\title{
TEORIA CRÍTICA E PÓS-MODERNISMO: PRINCIPAIS ALTERNATIVAS À HEGEMONIA FUNCIONALISTA
}

\author{
Marcelo Milano Falcão Vieira \\ Professor da FGV-EBAPE \\ E-mail: mmfv@fgv.br
}

Miguel P. Caldas

Professor Associado da Loyola University New Orleans

E-mail: mpcaldas@loyno.edu

\section{INTRODUÇÃO}

Observamos em outros números desta série (Vergara e Caldas, 2005) que, a despeito da predominância da ortodoxia funcionalista no campo de estudos organizacionais, ao menos desde o final da década de 1980, vertentes de resistência têm surgido para enfrentar tal hegemonia na área. Por um lado, ainda mais próximo do que Burrell e Morgan (1979) chamariam de "sociologia da regulação", surge a alternativa interpretacionista, à qual dedicamos um número da série. Por outro, afastando-se da sociologia da regulação, surgem a teoria crítica das organizações - mais orientada à mudança social - e, mais recentemente, abordagens pós-modernas em estudos organizacionais, cuja al ocação nos quadrantes de Burrell e M organ é problemática, pois, embora surja da contradição à ortodoxia positivista, nega igual mente a teoria crítica e os modelos mais radicais.

Neste último número da série, oferecemos aos vários docentes que não tiveram até hoje muito acesso a tais abordagens críticas e pós-modernas uma primeira aproximação às al ternativas epistemológicas mais recentes ao mainstream funcionalista. A eles dirigimos esta introdução, com o pedido de escusas aos muitos já iniciados, para quem ela parecerá um tanto básica. Além de introduzir os dois textos incluídos neste número como amostras da produção acadêmica crítica (no caso do texto de Valérie Fournier e Chris Grey) e da pós-moderna (artigo de Robert Cooper e Gibson Burrell), objetivamos aqui oferecer uma primeira aproximação a tais tradições alternativas, procurando mostrar as diferenças entre as duas vertentes, bem como sua diversidade interna, posto que, longe de serem monolíticas e convergentes, possuem grande diversidade evariância internas. Objetivamos também analisar brevemente sua utilização no Brasil nos últimos 20 ou 25 anos, bem como discutir possíveis direcionamentos para pesquisa futura dentro dessas tradições alternativas.

De início, precisamos esclarecer al guns pontos de partida, de forma que o leitor possa entender, consistentemente ao tópico em discussão, os pontos de vista aqui expressos de maneira crítica, reflexiva e relativa, e não confundi-los com uma pretensa expressão da "verdade", neutra e distanciada, tão típica da hegemonia funcionalista. Primeiro, devemos deixar patente que nós, autores desta introdução, não somos neutros, temos nossa posição e percepção de mundo, da teoria e do nosso campo, subordinadas a nossas posições sociais e contextos pessoais. Por exemplo, escrevemos ambos no contexto da análise organizacional, que de per se apresenta diferenças fundamentais em relação à análise crítica e pós-moderna em outros campos, como filosofia, artes, ou mesmo sociologia de forma geral. Ambos tivemos ao menos parte de nossa formação acadêmica no exterior, o que indica que nossa visão de mundo foi até certo ponto parametrizada por essa experiência. Ambos, embora um mais do que o outro, distanciamos nossa própria produção da tradição mais funcionalista, o que direciona certo viés em prol das vertentes alternativas ao mainstream funcionalista que aqui apresentamos. Ambos temos pessoalmente mais simpatia intel ectual e epistemológica por uma delas do que pela outra e, portanto, nela vemos mais potencial no Brasil. 
Segundo, precisamos também deixar patente que, para nós, a mera colocação dessas duas vertentes al ternativas - crítica e pós-moderna - no mesmo espaço (como aqui se faz, ou como também fez o próprio Handbook de estudos organizacionais [Alvesson e Deetz, 1999]) é problemática, e pode confundir mais do que elucidar o leitor não bem informado. Pode-se entender porque isso é feito: afinal, todo espaço editorial que ainda se consegue hoje em dia para vertentes epistemológicas alternativas à hegemonia funcional ista e positivista é raro e precioso. No entanto, a dificuldade reside em que, freqü entemente, o leitor ou aluno que têm sua primeira aproximação a essas al ternativas epistemológicas ao mainstream funcionalista por esse tipo de via - em que ambas são apresentadas conjuntamente - pode cair no erro de achar que, por serem justamente "alternativas", seriam semelhantes ou coincidentes. N ada mais incorreto: teoria crítica e pós-modernismo, de fato, têm em comum a sua clara intenção - dentre outras intenções distintas que cada uma apresenta - de serem vertentes epistemológicas resistentes e alternativas ao positivismo lógico. M as praticamente param aí as suas semelhanças, tal como a física newtoniana e a física quântica, que têm em comum a crença em leis abstratas que governam a natureza e 0 distanciamento da tradição pré-científica de união da ciência com a filosofia, mas que não são nem de longe idênticas ou coincidentes entre si; ou ainda as geometrias não euclidianas, e tantos outros exemplos do gênero. Críticos e pós-modernos têm em comum praticamente apenas a sua oposição ao mainstream que os precedeu. Vários textos no nosso campo, dentro e fora do Brasil, tendem a reincidir nesse erro e até certo ponto pluralizar essas duas vertentes distintas. Em nossa opinião, a união de correntes tão distintas sob o rótulo de "crítica" é um erro de ordem ontológica.

\section{TEORIA CRÍTICA}

Há muita confusão em torno da teoria crítica, principalmente na área de Administração. Um pouco dessa confusão deve-se ao desconhecimento de quem se dispõe a fazer uso da teoria crítica sobre sua origem e fundamentos teóricos e críticos. Outra parte deve-se ao oportunismo relativamente comum em áreas com característica aplicada, particularmente naquelas em que o mercado orienta a produção do conhecimento prático.

No ano de 2004 a TV Cultura produziu uma série de palestras, com renomados pensadores intitulada "Os Fundadores do Pensamento Social Contemporâneo". 0 filósofo M arcos N obre ficou encarregado de apresentar o tema "teoria crítica". Foi extremamente esclarecedora sua "aula" sobre a origem da teoria, bem como seus princípios fundamentais. São al gumas das idéias expostas por M arcos Nobre que passamos a reproduzir agora de forma comentada, relacionando-as, posteriormente, à área de Administração, com a intenção de que isso venha a esclarecer alguns problemas relacionados ao uso da teoria crítica na área. Ressaltamos que qualquer equívoco na interpretação das idéias apresentadas a seguir é de nossa exclusiva responsabilidade.

Nossa reflexão nesta seção divide-se em duas partes. N a primeira tratamos de uma questão de fundo, qual seja, os conceitos deteoria e de prática. Na segunda debruçamonos sobre a origem da teoria crítica e seus desdobramentos contemporâneos.

A questão da teoria e da prática é central para a teoria crítica devido a sua oposição à "visão tradicional" de teoria e de prática. Uma teoria é composta por um conjunto de hipóteses ou de argumentos utilizados para compreender fenômenos reais. Portanto, uma teoria visa a descrever como as coisas são, ou, nou tras pal avras, como a realidade é. Uma teoria, para ser considerada científica, deve, ainda, ser capaz de produzir prognósticos, ou seja, de dizer o que está para acontecer se as condições precedentes forem satisfeitas. Uma teoria é corroborada ou refutada quando os prognósticos baseados nas suas hipóteses se confirmam ou não. Dessa forma a teoria se opõe à prática. Conhecer e agir são, portanto, coisas distintas.

Com isso decorre uma questão central para a teoria crítica: como trabalhar a noção de emancipação - que, como veremos a seguir, é o ponto central da teoria - sem que a teoria esteja vinculada à prática transformadora? Como fugir da distinção entre descrição e prescrição? Para solucionar esse problema a teoria crítica questiona a distinção vigente entre teoria e prática a partir do uso da categoria "crítica". Criticar não significa abdicar de conhecer o mundo como eleé, tampouco de pensar como ele deveria ser.

A base da teoria crítica está, pois, no seguinte postulado: é impossível mostrar as coisas como realmente são, senão a partir da perspectiva de como elas deveriam ser. $\mathrm{N}$ a verdade, 0 "dever ser" se refere às possibilidades não realizadas pelo mundo social. N ão tem caráter utópico, mas analisa o que o mundo poderia ter de mel hor se suas potencialidades se realizassem. A identificação das potencialidades permite entender mais claramente como 0 mundo funciona e, dessa forma, identificar os obstáculos à real ização das suas potencialidades. Assim, a teoria crítica aponta para a prática a partir da realização desses 
potenciais, por meio da identificação e rompimento dos obstáculos. É a teoria no ato. 0 ato é aquele da realização dos potenciais do mundo, e tais potenciais são de natureza necessariamente emancipatória.

Para os teóricos críticos, aqueles que se dedicam apenas a descrever o mundo como ele é acabam por fazê-lo sempre de forma parcial e incompleta, pois abdicam de identificar o que ele poderia ser, ou seja, o que ele tem potencialmente de melhor. Isso nos remete à segunda parte de nossa reflexão: a origem da teoria crítica e seus desdobramentos contemporâneos.

A teoria crítica aponta para a prática como a realização dos potenciais emancipatórios do mundo. Para tanto, parte do princípio de que o mundo se organiza em torno de dois grupos de tendências estruturais. 0 primeiro grupo de tendências são os agentes da permanência dos obstáculos à realização das "potencialidades meIhores" do mundo. 0 segundo grupo são os agentes potenciais da ação que permite superar os obstáculos. Assim, a teoria crítica dá sentido à ação e a ação vira objeto da teoria. Portanto, os embates políticos e ideológicos são centrais na teoria. Ela não se quer neutra.

O primeiro a utilizar o termo "teoria crítica" foi Horkheimer no livro Teoria tradicional e teoria crítica, publicado em 1937. N ele o autor deixa explícito que "produz teoria crítica todo aquele que quer continuar a obra de Marx". Ao afirmar isso, Horkheimer define o campo teórico da teoria crítica como o marxismo, e este como um campo de conhecimento distinto de outros campos.

Jameson (1991) diz que a importância contemporânea de $M$ arx se deve exatamente ao fato de que ele foi 0 filósofo político que se dedicou a tratar do capitalismo. N este momento de exuberância e exacerbação do capitalismo, como ignorar que Marx tem uma importância relativamente mais destacada? Quem, senão ele, forneceu a maior base da crítica ao que mais tarde se denominou capitalismo?

Entretanto, cabe salientar que, mesmo reconhecendo a grande importância e contemporaneidade de Marx, a visão de que "faz teoria crítica todo aquel e que quer continuar o trabalho de Marx" é, no nosso entendimento, uma visão parcial e, em certa medida, excludente. Wacquant (2004), por exemplo, esclarece que existem dois sentidos para a noção de crítica, no que se refere à sua origem: o primeiro vem de Kant e diz respeito à avaliação de categorias e de formas de conhecimento com 0 objetivo de determinar sua validade cognitiva e seu vaIor. 0 segundo é de M arx, cuja noção está ligada à análise da realidade sócio-histórica com o objetivo de expor as formas de dominação e exploração que a definem. Para
Wacquant, o pensamento crítico mais frutífero é aquele que se situa na confluência dessas duas tradições, ou seja, da critica epistemológica e da crítica social, questionando sistematicamente tanto as formas estabel ecidas de conhecimento como as de vida coletiva.

A teoria crítica não pode ser resumida num conjunto de idéias ou de teses imutáveis, pois, de acordo com o próprio $M$ arx, a verdade é temporal e histórica. 0 teórico crítico é, portanto, aquele que está sempre mudando, mas ao mesmo tempo orientado pelo princípio da transformação social e da emancipação. N esse sentido, podese ser teórico-crítico contemporâneo tendo rompido com Marx, mas não com as categorias centrais da crítica, que envolvem criticar o positivismo como forma estabel ecida de conhecimento e o mercado como forma estabelecida de vida coletiva. Para nós, da área de Administração, essa é uma informação fundamental, pois a partir daí podemos separar de forma definitiva quem produz teoria crítica de quem não a produz e apenas se apropria indevidamente dela.

Com relação à base da crítica ao positivismo, no início desta seção referimo-nos brevemente a ela ao tratarmos da dissociação entre teoria e prática. Passamos agora a outro breve relato, 0 da base da crítica à forma dominante de organização social: o mercado. Retomando a idéia de que não se deve abdicar de conhecer o mundo como ele é, a primeira tarefa da teoria crítica é compreender o mercado e sua unidade central, qual seja, a mercadoria. 0 mercado é regido pela lógica da troca. Ela determina os val ores no mercado, e nele tudo vira produto capaz de ser trocado; tudo adquire valor de troca.

É na Revolução Industrial, quando o grande avanço tecnológico propiciou que a riqueza acumulada no campo se transferisse para as fábricas e centros urbanos por meio da aquisição de tecnologia, que surge a separação entre a força de trabal ho e os instrumentos que permitem produzir bens. É o nascimento do capitalismo como uma construção histórica. Sem ela o capital ismo não teria existido. Evidencia-se, assim, a nova divisão estrutural da sociedade: 0 capital e o trabalho, que se organizam no mercado. 0 mercado, portanto, congela as desigualdades iniciais entre capital e trabalho e as aprofunda.

Não cabe aqui descrever as formas com que o mercado aprofunda essas desigualdades iniciais. Há literatura abundante sobreo assunto na área, principalmente aquela ligada à análise do processo de trabal ho e ao controle nas organizações. É importante, sim, evidenciar que o mercado aparece como instituição neutra, onde trocas justas são realizadas. Além disso, o mercado promete realizar a liberdade e a igualdade. Ora, sabe-se de longa 
data que as trocas entre indivíduos e organizações não são trocas iguais simplesmente pelo fato de que ambos detêm recursos de poder consideravelmente diferentes, em volume também diferente. Sabe-se, ainda, que liberdade e igualdade não são conceitos aplicáveis quando a lógica é a da competição.

A teoria crítica dedica-se, assim, a examinar o mercado e suas relações à luz da emancipação, que significa a busca da realização concreta da liberdade e da igualdade. 0 conceito de emancipação está no centro da teoria crítica, atribuindo-Ihe unidade. Podemos, portanto, enunciar dois princípios básicos da teoria:

- orientação para a emancipação do homem na sociedade. Permite compreender a sociedade e agir. Não se limita a compreender o mundo, mas examina-o visando possibilidades;

- manutenção de comportamento crítico. 0 teórico crítico mantém e realimenta seu comportamento crítico frente a tudo que existe, sem se conformar com o que é dado como descrição do real.

A teoria crítica não admite a neutralidade positivista por achá-la parcial. N esta, a distinção entre cientista e cidadão é um pressuposto básico, enquanto naquela é uma impossibilidade lógica.

Uma vez difundida essa teoria em vários campos das ciências sociais, logo apareceram teóricos críticos em Administração, especialmente na área de estudos organizacionais, opondo-se ao mainstream funcionalista. Enquanto no Brasil esse grupo teve forte influência no campo, como discutimos a seguir, no mundo anglo-saxão sua recepção foi menos acolhedora e sofreu ampla resistência (para uma revisão, veja, por exemplo, Alvesson, 1987). Como qual quer grupo científico que tende a politizar-se, que busca definir territórios e excluir desavenças, e também combater a fal ta de espaço editorial e de debate para abordagens não positivistas na hegemonia norte-americana, muitos desses teóricos críticos estrangeiros acabaram se organizando em torno do grupo hoje conhecido como Estudos Críticos em Administração (Critical Management Studies, ou CMS). O CMS tornou-se hoje, depois de quase duas décadas de constituição, um grupo restrito e até certo ponto restritivo de teóricos, com suas próprias definições e parâmetros das fronteiras do que seria ou não crítico em estudos organizacionais (veja, por exemplo, Alvesson e Wilmott, 1992). Mas é preciso notar (como discutiremos mais adiante) que tal quase-associação eseus parâmetros de inclusão crítica não estão ainda definitivamente aceitos e resolvidos, nem devem necessariamente pautar o seu uso e expansão em terra brasilis.
$\mathrm{Na}$ área de Administração no Brasil, temos a tradição de pensamento crítico, embora ele não represente 0 mainstream da academia nacional. U m ótimo exemplo é o trabalho de Alberto Guerreiro Ramos $(1989,1996)$, particularmente nas obras A redução sociológica e a nova ciência das organizações. Na primeira, criticava a ciência domesticada, fundamentada na reprodução não criativa e distanciada do nosso tempo-espaço e, conseqüentemente, dos nossos problemas; incapaz, portanto, de oferecer soluções apropriadas e emanci patórias. N a segunda, criticava o mercado como forma dominante de organização da vida social. Chamava a atenção para os problemas decorrentes da expansão do mercado e propunha a "delimitação dos sistemas sociais". Maurício Tragtenberg (1971, 1980a, 1980b e 1980c) dedicou parte da sua obra à análise da teoria da Administração como uma ideologia. Argumentava que a Administração dedica-se ao estudo da legitimação burocrática do poder eque esta possui caráter repressivo, dada sua ênfase no controle sobre o homem. Seu fazer acadêmico não era "neutro", como deixava claro em sua produção. Fernando Cláudio Prestes M otta (1985, 1986a, 1986b, 1986c, 1987, 1988, 1990) desenvolveu estudos sobre burocracia, poder e tecnologia, educação e, mais tarde, sobre cultura. Explicitava ao tempo em que criticava o que chamou de esforço constante e sistemático das teorias administrativas dominantes em fundir racionalidade substantiva e instrumental como modo de aperfeiçoar as formas de dominação sobre o indivíduo. Também acreditava na necessidade e possibilidade do desenvolvimento de novas teorias, que possuíssem caráter emancipatório e apropriado ao nosso tempo-espaço.

Guerreiro Ramos, Tragtenberg e Prestes Motta trabaIharam de forma crítica, sempre pensando em como nossa sociedade poderia ser e não é. 0 sucesso e o reconhecimento que esses autores obtiveram, acreditamos serem devidos a esse fato, que atribui, por si só, relevância e pertinência ao trabalho do cientista-cidadão. Sua relevância é auto-evidente.

Esses autores, que, pode-se afirmar, iniciaram a tradição crítica na área de Administração no Brasil, formaram escolas de pensamento e deixaram seguidores. Vários trabal hos contemporâneos são inspirados diretamente em sua obra, na tradição por el es fundada. Algumas escolas e programas de pós-graduação atribuem ênfase maior a essa tradição do que outras. A Escola Brasileira de Administração Pública e de Empresas e a Escola de Administração de Empresas de São Paulo, ambas da Fundação Getúlio Vargas, foram, em certa medida, a "casa" desses pensadores (Maurício Tragtenberg e Fernando Prestes M otta em São Paulo e Guerreiro Ramos no Rio) e, talvez 
por essa razão, mantenham presente de maneira mais forte essa tradição. Guerreiro Ramos ainda tem influência em trabal hos desenvolvidos no Curso de Pós-Graduação em Administração da Universidade Federal de Santa Catarina, onde também lecionou. Entretanto, como afirmamos, suas idéias continuam a ter ressonância no trabalho de diversos pesquisadores brasileiros (veja, por exemplo, Tenório 2002a, 2002b, 2004; e Paula, 2001, 2002, 2004a, 2004b, 2005a, 2005b).

A produção crítica brasileira não se limita, entretanto, à tradição mencionada anteriormente. A título de ilustração, podemos citar os trabalhos com perspectiva marxista de Faria (2001, 2004, 2005) e de Misoczky (2002), os de realismo crítico de Faria (2004, 2005a, 2005b), e de Faria e Wensley (2005), os de Vieira e Vieira (2003, 2004) com uma perspectiva geopolítica, e, ainda, os que assumem a perspectiva conhecida do CMS, como os de Davel e Alcadipani $(2002,2003)$. Um ótimo exemplo do vigor, das perspectivas e dissonâncias da teoria crítica no Brasil pode ser visto no recente debate realizado na Revista de Administração Contemporânea (RAC), no primeiro número de 2005, entre Maria Ceci Misoczky e Jackeline Andrade, Alexandre Faria e Rafael Alcadipani. N ele os autores expõem suas idéias, deixando claras suas diferenças e abrindo, dessa forma, o mundo das diferentes possibilidades de se fazer crítica em Administração em geral, e particularmente nos estudos organizacionais.

0 texto sobre teoria crítica que nos cabe introduzir, intitulado $\mathrm{N}$ a hora da crítica: condições e perspectivas para estudos críticos de gestão, de Val érie F ournier e C hris Gray, apresenta uma visão da história do já mencionado CMS (Critical Management Studies) e sua quase-associação. N esse sentido, apresenta uma visão parcial da teoria crítica em estudos organizacionais. É evidente que há crítica e teoria crítica para além das fronteiras do CMS. Mas, para quem quer conhecer o que se pode chamar de mainstream dos estudos críticos na área de Administração, o texto é muito elucidativo.

Os autores descrevem brevemente as origens dos estudos críticos, relembram a tradição dos estudos sobre 0 processo de trabalho e informam que, na sua perspectiva, os estudos críticos em Administração apenas se tornam um corpo sistematizado de conhecimento na década de 1990, quando têm início as conferências com o mesmo título. Atribuem seu surgimento a uma onda de oposição, na academia britânica, à N ova Direita, capitaneada pela primeira-ministra $M$ argareth Thatcher e que originou a gerencialização (managerialization) da administração governamental. Passam depois para a discussão das disputas internas no âmbito dos estudos críticos em Administração e concluem com um tímido questionamento do argumento inicial de que o Reino Unido éo espaço de formulação e disseminação da crítica.

Ao situar a crítica no Reino Unido e ao caracterizá-lo como o lugar por excelência, os autores direcionam a natureza da crítica, adotando uma visão colonialista da questão. Assim, para nós, essa crítica deixa de ser crítica por perder seu caráter emancipatório, que, como vimos, é essencial à definição de teoria crítica. Além disso, os autores parecem situar a crítica no âmbito das escolas de negócios do Reino Unido. Ao construir esse espaço institucional, a crítica perde força, pois adquire caráter de "crítica autorizada", legitimada e preocupada em ser positiva (outra teoria do mainstream, a teoria institucional, particularmente o neo-institucionalismo sociológico, é capaz de explicar adequadamente este ponto!).

Como já afirmamos, embora achemos que o CMS tenha acabado por estabelecer um tipo de "mainstream de estudos críticos em Administração", acreditamos que a teoria crítica não se limita ao Reino Unido, e tampouco ao CMS. Parece-nos importante lembrar que, no contexto europeu, pel o menos uma outra importante tradição crítica existe: a francesa, ainda que não possa ser facilmente identificada por alguma marca. N ão é possível ignorar a tradição da qual fazem parte, por exemplo, Sartre, Althusser, Poulantzas, Foucault e Bourdieu. Recentemente, o trabal ho de Solé $(2003,2000)$ também têm tido al guma ressonância no Brasil. O bviamente que essa lembrança mantém uma perspectiva eurocêntrica e, portanto, ignora a tradição crítica dos países não europeus. Apenas para ficar no contexto latino-americano, lembramos os desenvolvimentos teórico-práticos que têm por base a filosofia da libertação, e que passam pela teologia, pela educação e pela cultura (veja, por exemplo, Freire, 1994).

No Brasil, o espaço em que trabalhamos a crítica é bem mais amplo do que a academia britânica permite e, seguramente, deve optar por uma visão apropriada ao nosso tempo-espaço, diferente do eurocêntrico. Alguns autores brasileiros, entretanto, parecem preferir a crítica institucionalizada. Ao defenderem o pluralismo das abordagens que se abrigam sob o manto do CMS (Alcadipani, 2005), acabam por adotar uma posição conservadora, de manutenção do status quo, desvinculada de um dos princípios da teoria crítica, a ação transformadora. A revista Ephemera: Theory \& Politics in Organization, em 2004, oferece uma ótima reflexão sobre essa questão, particularmente no editorial de Steffen Böhm e Sverre Spoestra (Böhm e Spoestra, 2004) ena resenha de Stephen Ackroyd (2004) sobre o livro Studying M anagement Critically, organizado por Alvesson e Willmott (2003). 
O espaço dos estudos organizacionais no Brasil nos possibilita a oportunidade de romper com a dependência acadêmica. Permite-nos pensar que só é possível discutir emancipação quando resgatarmos a consciência da nossa posição relativa no mundo, e que dela decorrem outras relações no âmbito interno de nossas organizações. Talvez seja útil o resgate dos conceitos de centro e periferia. Eles nos permitem ações transformadoras, pois não contêm o fal so rótulo de neutral idade que esconde, quase sempre, relações perversas de dominação.

\section{PÓS-MODERNISMO}

0 primeiro desafio para introduzir o leitor ao movimento pós-moderno e suas possibilidades é sua mera definição. Primeiramente, há múltiplas facetas e subcorrentes pós-modernas; segundo, há formas de defini-lo, e cada uma tende a não reconhecer as outras como "legitimamente pós-modernas" ( N orris, 1990). M as, de forma genérica, pode-se dizer que o pós-modernismo corresponde a um movimento teórico multidisciplinar que vai da filosofia à estética, envolvendo as artes, a sociologia chegando ao campo dos estudos organizacionais. 0 denominador comum é a resistência à modernidade e, em particular, a crítica à razão iluminista (veja, por exemplo, Harvey, 1993; Clegg, 1990; Wood, 1999).

Obviamente, apenas se pode entender a abordagem pós-moderna a partir do entendimento da chamada "era pós-moderna", isto é, o conjunto particular de eventos e condições que caracterizariam o final do século XX einício do século XXI, e que um grupo de filósofos e cientistas sociais entendeu constituir uma ruptura em relação à era moderna (Lyotard, 1984).

Muitos autores, como Harvey (1993) e Derrida (1967), caracterizam a chamada "era pós-moderna" por diversos elementos, como a globalização; o relativismo e o pluralismo, caracterizados pela dissi pação da objetividade e da racionalidade, tidas como tipicamente modernas; a espetacularização da sociedade, marcada pela central idade da mídia e da imagem; a cultura de massa; a normalização da mudança pela perpetuação de tudo como volátil e transitório; o papel do indivíduo na sociedade primordialmente como consumidor; e a comoditização do conhecimento.

Mas será essa uma ruptura com a modernidade, ou será um estágio mais recente e transformado de modernidade tardia? 0 pós-modernismo como movimento intelectual se define justamente por aqueles que vêm no fim de sécuIo XX uma ruptura com a era moderna, e pelo argumento de que nossas percepções de mundo, a estética, a ciência e o conhecimento devem também adequar-se a essa mudança. Portanto, as convicções modernistas e os resíduos do projeto iluminista devem ser abandonados.

É importante salientar, no entanto, que há um conjunto significativo de autores que não entendem ser a "pós-modernidade" uma ruptura com a modernidade, e sim um estágio "tardio" da modernidade - como Habermas ou Giddens (1991a, 1991b) - ou como estágios distintos da modernidade, como o conceito de "modernidade sólida" e "modernidade líquida" de Bauman (1998, 2001). Habermas, por exemplo, parece sintetizar o que se poderia chamar de "crítica modernista ao pós-modernismo". Para ele, ao negar a crítica e a razão como um todo, bem como o projeto iluminista, os pós-modernos enganam-se duplamente. Primeiro, porque o projeto iluminista ainda não estaria completo, o que indicaria que a modernidade perdura; e, segundo, porque sem razão e crítica negariam valor ao indivíduo, e com isso acabariam por levar a sociedade ao totalitarismo.

Por sua vez, os teóricos pós-modernistas reagem a essas críticas entendendo serem "lamentos modernistas em um mundo pós-moderno", como crédulos incautos do potencial "salvador" da humanidade de si mesma, ou como racionalizantes da razão e do universalismo iluminista (veja, por exemplo, Lyotard, 1984).

Pós-modernistas devotos como Lyotard acabaram promovendo o movimento pela radicalização de suas visões de mundo, conhecimento e ciência, e pelo seu deliberado afastamento dos movimentos críticos, como Habermas e outros teóricos de Frankfurt, que percebem como arraigados a um modernismo ultrapassado. Para eles, a crença na razão e no projeto iluminista não faz mais sentido no mundo pós-moderno. Tanto a teoria crítica quanto os model os a que esta se opõe constituiriam todos, de per se, metanarrativas, model os universais e generalizações, que os pós-modernistas negam e das quais quase se divorciam por completo.

Criticando os modernistas e a sua fé na razão iluminista, os autores pós-modernistas tendem a argumentar que a racionalidade é muito mais difusa do que 0 Iluminismo supunha, eque o conhecimento apenas pode ser entendido à luz do tempo, espaço e contexto social em que é construído por indivíduos e grupos. Portanto, indicam, entre outros métodos, o uso de Derrida (2004) e do conceito de desconstrução desse conhecimento construído, para revelar e entender seus pressupostos e suas contradições. Segundo Derrida, as contradições no texto e no discurso revelariam tanto os múltiplos sentidos do conhecimento como a dinâmica e o contexto de sua construção. Outra abordagem típica do pós-modernismo em 
ciências sociais é o uso de genealogias, inspiradas em Foucault (1987, 1988), pelas quais, usando métodos historiográficos, esses teóricos procuram "desfamiliarizar" construções modernistas e expor suas contradições e manipulações internas.

No âmbito organizacional, o movimento pós-modernista chega, em especial, por meio de teóricos europeus vindos da tradição pós-estruturalista, e por críticos da tradição positivista em sociologia e em estudos organizacionais (veja Calás e Smircich, 1999; Hassard, 1993; Hassard e Parker, 1993; ou Chia, 1995, para uma evolução do movimento).

0 artigo da perspectiva pós-moderna incluído neste número da série é um excelente ponto de partida para o leitor interessado em entender melhor as abordagens pósmodernas, seus principais postulados e suas origens no âmbito organizacional. 0 texto de Cooper e Burrell, M odernismo, pós-modernismo e análise organizacional: uma introdução é, na verdade, a introdução ao que deveria ser uma série de quatro números da revista Organization Studies sobre a perspectiva pós-moderna em estudos organizacionais, que cobriria suas origens e contribuições. Os artigos nos números subseqüentes deveriam cobrir as contribuições de Derrida (Cooper, 1989), Habermas (Burrell, 1994) e Luhmann (ainda não publicado quando do fechamento do presente artigo, em fins de 2005, embora o texto de Hernes e Bakken [2003] possa bem substituí-lo). Sugere-se fortemente ao leitor mais interessado nessa corrente que, como complemento do artigo aqui incluído, consulte também os números subseqüentes da série.

Como mostram Cooper e Burrell, a base da análise pós-moderna - dentro e em volta do campo de estudos organizacionais - inicia-se pela oposição a teóricos sociais críticos que cunhavam de "modernistas" (como Habermas, Luhmann e Bell), em função do que afirmavam ser uma crença infundada de que a humanidade, por meio da razão e do "progresso", poderia aperfeiçoar a si mesma. Os primeiros pós-modernistas em estudos organizacionais, inspirados nos trabalhos de autores como Derrida, Lyotard e Foucault, tipicamente se definiam por dois elementos. Primeiro, pela radical oposição a esse que chamariam de viés "racionalista etnocêntrico" dos teóricos modernistas, mesmo os chamados "críticos". Segundo, pela firme oposição ao positivismo que impera(va) na teoria social hegemônica, sustentado pelo amplo contingente de teóricos pós-estruturalistas que, desde o principio, juntaram-se ao movimento, mas que não encontravam nos argumentos da teoria crítica um continente para suas preocu pações mais contemporâneas (Alvesson e Deetz, 1999; Chia, 1995).
Autores como Gibson Burrell e John Hassard, no Reino Unido, e M arta Calás e Linda Smircich, nos Estados Unidos, foram fundamentais na disseminação do movimento em estudos organizacionais, a princípio, mas não apenas pelo aporte de perspectivas e metodologias desconhecidas às teorias até então utilizadas no campo. Autores de orientação pós-modernista se multiplicavam, e dentro do escopo geral de crítica à modernidade e ao positivismo, focaram na relevância do discurso, do relativismo, da personal ização e das relações de poder no que chamam de "construção" da verdade e do conhecimento.

Armados de metodologias desconstrutivas, teóricos pósmodernistas em estudos organizacionais partiram para a crítica a elementos da modernidade que se enraizariam em pressupostosiluministas, freqüentemente usando metodologia de análise de discursos e narrativas (Hassard, 1993; Hassard e Parker, 1993; Chia, 1995). Obviamente, não apenas de análises desconstrutivas vive o pós-modernismo em estudos organizacionais. Os teóricos pós-modernistas também popularizaram o uso de metodologias de inspiração pós-estruturalista, especialmente as análises geneal ógicas e historiográficas inspiradas no trabal ho de Foucault $(1987,1988)$ : são exemplos em análise organizacional, entre outros, o trabal ho de Sewell eWilkinson (1992), que traça a geneal ogia do movimento da qual idade e relaciona práticas de qualidade total com o panóptico, e o de Towney (1993), que desenha a genealogia da função de RH e a compara com censos populacionais, normatizantes e familiarizados pelo costume.

No Brasil, como já apontou Wood (1999), poucos foram os adeptos de abordagens pós-modernistas em estudos organizacionais, embora sua produção esteja longe de ser pouco significativa. É verdade, no entanto, que parece ser bem mais fácil encontrar os sinais da influência do movimento pós-modernista na produção brasileira em organizações, por exemplo, por meio da influência de seus expoentes (Foucault, Derrida, Baudrillard e Latour) do que pela assunção direta desse rótulo pelos pesquisadores. De fato, al guns poucos autores claramente declaram essa inclinação em suas publicações ( por exemplo, Tonelli e Alcadipani [2000] em comportamento organizacional, M endes [2004] em organizações, ou Casotti [1998] em marketing), enquanto muitos outros parecem limitar-se a utilizar referências ou metodologias de inspiração pós-moderna em meio a outras abordagens, a despeito de, com elas, o pós-modernismo poder apresentar evidente disparidade e contradição.

Balanços recentes das abordagens pós-modernas em estudos organizacionais evidenciam avanços sentidos também no Brasil. Calás e Smircich (1999) mostram 
que, após quase duas décadas da influência do movimento no campo, quatro vertentes teóricas parecem ser as principais "herdeiras" do pós-modernismo em análise organizacional, e que nele ainda residem com forte potencial de extensão e contribuição: (i) teorias feministas (ou de gênero) pós-estruturalistas, (ii) análises póscolonialistas; (iii) teoria actor network (actor network theory, também chamada de teoria da translação), ${ }^{1}$ além da (iv) análise desconstrutiva de discursos e narrativas sobre conhecimento.

Quanto à primeira, teorias feministas pós-estruturalistas, os trabal hos da própria Marta Calás (Calás, 1992; Calás e Smircich, 1999b) e de Calvert e Ramsey (1992) são bons exemplos. São ilustrações de uma aproximação brasileira a esse tipo de perspectiva, entre outros, os trabalhos de Cappelle et al. (2004) e de Andrade et al. (2002). Na segunda vertente, ligada à análise pós-estruturalista, que ficou conhecida como teoria pós-colonialista, bons pontos de partida podem ser vistos, por exemplo, em Bhabha (1995) ou em Young (2001). Embora essa linha não tenha sido ainda devidamente explorada no Brasil, uma primeira aproximação pode ser vista em Caldas e Alcadipani (2006). Na vertente da teoria actor-network, ou da translação, a influência do trabalho de autores como os franceses Bruno Latour (1992, 1994, 1997) e Michel Callon (1999), e o britânico John Law (1994), pode ser melhor entendida, no âmbito organizacional, por revisões abrangentes como a de Law eH assard (1999), ou por aplicações práticas como a deKaghan e Phillips (1998). Como a vertente anterior, esta linha teórica é muito pouco explorada em análise organizacional no Brasil, tendo sido publicados apenas al guns estudos ligados à área de tecnologia da informação (por exemplo, Souza eFontana, 2005). Por fim, sobre ajá mencionada análise de narrativas, exemplos desse tipo de pesquisa em estudos organizacionais incluem, entre outros, o trabalho de Kilduff (1993); no Brasil, a pesquisa de Lengler, Vieira eF achin (2002) éuma ótima ilustração de aplicação local.

Obviamente, um movimento tão polêmico e tão abrangentemente abrasivo às abordagens anteriores não poderia deixar de ter seus desafetos e críticos, muitos deles de alto calibre, como já brevemente mencionamos no início desta seção. Primeiramente, alguns críticos sugerem que o movimento não passa de um aglomerado de descontentamentos e argumentos que têm entre si apenas a insistente antipatia ao modernismo e aos projetos iluministas (veja resumo dessa e de outras críticas em Norris, 1990). Em segundo lugar, diversos autores de peso, como Habermas, Giddens e Bauman, negam-se a aceitar a idéia de ruptura de uma época moderna para uma pós-moderna. Preferem entender a realidade pósmoderna como um estágio mais recente ainda dentro do escopo da modernidade (uma discussão nesse sentido pode ser vista em Berman, 1982). Em terceiro lugar, críticos do pós-modernismo também questionam a ausência de uma proposição ou contribuição positiva que derive da "desconstrução" pós-modernista ou da exposição das premissas de teorias prevalecentes, parafraseando a expressão popular, como exercício intelectual: parece ser interessante, mas para que serve? Ou, afinal, o que existe depois da desconstrução? (Calás e Smircich, 1999). M esmo autores como David Harvey sugerem que se torna difícil a sustentação de um movimento que nada tem a propor ao progresso, porque questiona a noção básica de progresso, ou que nada tem a sugerir para um mundo mais justo, porque não compartilha da percepção de universalidade nem sequer de princípios como justiça ou eqüidade. Habermas chega a argumentar que, no limite, o pós-modernismo não deixa de ser um movimento conservador, que preserva o status quo, pois, a ser deixada em suas mãos, nenhuma mudança jamais deverá ser feita, restando-nos a letargia de um subjetivismo radical (sobre esse debate no pensamento de Habermas, veja resumo em White, 1988). E por fim, em quarto lugar, críticos mais radicais, com argumentos nessa mesma direção, chegam a argumentar que os teóricos pós-modernistas têm pouco a oferecer simplesmente porque não teriam muito a dizer. Alan Sokal, por exemplo, sintetiza esse tipo de ponto de vista segundo o qual o movimento pós-modernista não passaria de exercícios de verborragia e semântica, sem maior significado ou propósito além do de demarcar um território para si mesmo. Para provar seu argumento, Sokal - um físico - submeteu a um periódico pós-modernista um artigo propositadamente sem sentido (sobre perspectivas pós-modernas da física e da matemática), o artigo foi aceito e publicado (veja relato e discussão em Sokal e Bricmont, 1998).

Talvez não seja preciso chegar a tanto. Não há duvidas que o pós-modernismo trouxe importantes contribuições, ao menos em análise organizacional, como discutiremos a seguir, na conclusão.

\section{CONSIDERAÇÕES FINAIS}

A teoria crítica e o pós-modernismo são alternativas ao modo de gerar conhecimento. Assim, podem trazer avanços e inovações em uma área como a nossa, tão afeita à reprodução do conhecimento.

Quanto à teoria crítica, acreditamos que ela pode ser 
muito útil à Administração em geral, e ao campo dos estudos organizacionais em particular. Acreditamos que essa abordagem é um dos caminhos possíveis na busca da emancipação do homem, na direção de uma sociedade melhor e mais justa. $\mathrm{Na}$ academia, ela ajuda a construir um tipo de conhecimento e a realizar um tipo de ciência mais apropriados, no sentido do Guerreiro Ramos, às nossas raízes históricas e culturais. Isso não significa isolamento ingênuo ou romantismo em relação ao local, mas sim uma posição de tomada de consciência sobre nosso papel no mundo. Para tanto, parece-nos imprescindível evitar a crítica dócil, que opera quase como uma nova "gaiola de ferro", uma vez que tem origem em uma visão do norte sobre o sul ou, se o leitor preferir, do centro sobre a periferia. Isso nos emancipa? Isso nos garante desenvolvimento? Talvez a boa crítica seja aquela fruto do diálogo respeitoso entre o norte e o sul.

Outro ponto importante sobre esse tema é a necessidade de que nossos textos sejam usados por outros autores nacionais para o debate de idéias. As críticas não devem ser tomadas como pessoais, como costuma ser nossa tradição. Entretanto, é importante não confundir isso com o caráter positivo da crítica. Como dizia Horkheimer, um elemento de negatividade é importante. A crítica positiva, ou construtiva, na linguagem mais comum, guarda em si um caráter da manutenção. A transformação se dá na via oposta. Seja como for, só elas, as críticas, são capazes de produzir reflexividade e conduzir ao avanço acadêmico.

No que se refere ao pós-modernismo, no campo de estudos organizacionais, é importante reconhecer que 0 movimento trouxe uma contribuição significativa. Entretanto, com essas contribuições, o pós-modernismo parece trazer também seus próprios dilemas e paradoxos, como discutido na seção anterior. Entendemos ser nosso dever discutir aqui, um pouco, tanto essas potencialidades quanto suas limitações.

Quanto às potencialidades, o pós-modernismo legitimou metodologias como a desconstrução de narrativas e análises geneal ógicas que vêm crescentemente se expandindo nas últimas décadas. Trouxe também ao campo, em função da visão representacionista da teoria, a pertinência de se demandar do pesquisador ou do ator produtor de conhecimento a explicitação do propósito (para que e para quem se cria conhecimento) e do contexto (tempo, espaço e ambiente) em que esse conhecimento é produzido. E trouxe, além disso, a forçosa revisão da propriedade de elementos da modernidade e do projeto iluminista que se manifestam nas organizações de hoje. Enfim, sem dúvida ofereceu ao campo a visão fresca de que uma teoria pode ser construída de forma distinta do que até então se praticava (Calás e Smircich, 1999). Mais especificamente no Brasil, o pós-modernismo de fato oferece um sem-número de novos caminhos, metodologias e questões de análise em estudos organizacionais.

Do ponto de vista metodológico, embora Derrida argumente não ser essa uma metodologia apenas, é sem dúvida bem-vindo o uso rigoroso de análise e desconstrução de narrativas, bem como competentes análises genealógicas. Talvez muito da nossa produção no campo que tenta distanciar-se do funcional ismo esteja excessi vamente baseada em ensaios, e a crítica de fal ta de base empírica demande esse tipo de aporte metodológico. E talvez muito da nossa produção de conhecimento seja descontextualizada, e o sujeito desse conhecimento de fato possa ser colocado em questão.

Do ponto de vista temático, vários dos mais atuais temas preferidos pelo movimento parecem ter grande potencial no Brasil. Por exemplo, a perspectiva pós(e neo)colonial ista parece bem apropriada a um país e uma realidade que vivem à margem de países ditos desenvolvidos, em uma relação que está longe de ter sido bem mapeada e resolvida, inclusive no campo organizacional. Os estudos pós-estruturalistas de gênero também parecem especial mente apropriados: por um lado, o crescimento da produção brasileira em temas de gênero ressente-se das mesmas limitações que o paradigma funcionalista, as quais as abordagens (e especialmente metodologias) pós-modernas podem ajudar a superar. Por outro lado, o foco em gênero poderia aqui ser expandido para a análise de outras dimensões e desconstruções de exclusões, como de raça, condição social e orientação sexual. Afinal, a verdade é que o país e suas organizações ainda sofrem os elementos e múltiplos efeitos das muitas exclusões que reproduzimos, e que nossos teóricos têm majoritariamente ignorado.

No entanto, é difícil deixarmos de mostrar os dilemas que uma leitura mais purista do pós-modernismo pode trazer. Em um mundo crescentemente conflituoso, abundante em iniqüidades e em miséria, a postura pós-modernista radical de questionar o projeto e as potencialidades da crítica e da autonomia humana parece, no mínimo, de difícil aceitação.

Ou talvez, como diria Zygmunt Bauman, aceitá-las por completo fosse até imoral. Em recente trilogia - G lobalização (1999), Em busca da política (2000), e A modernidade líquida (2001) -, Bauman analisa as mudanças nas condições da vida social e política entre fins do século XX e início do século XXI. Para ele, essas mudanças caracterizam uma transformação, mas dentro da modernidade. Enquanto em estágios anteriores a modernidade 
parecia sempre preservar al gum el emento de permanência e imutabilidade que Ihe daria sentido, nos dias de hoje, ditos "pós-modernos", tudo, inclusive a identidade do indivíduo e as relações humanas, teria se tornado efêmero e volátil. Bauman acredita fundamental mente na busca da autonomia. A transmutação da identidade, nesse mundo de "modernidade fluida", pode enganosamente nos levar a crer que somos livres para escolher o que somos e quem somos. Porém, Bauman não vê nisso liberdade ou efetiva emancipação, mas a gênese, nesta modernidade fluida, de um mundo excessivamente egoísta e competitivo, onde não há lugar para solidariedade, e onde se abre espaço para uma evolução ainda mais sinistra do capital do que na época do surgimento do capital ismo. 0 autor admite que não oferece soluções, embora sua defesa da política e da assunção do papel de cidadão pelo indivíduo seja pungente. Contudo, defende sua busca incansável do diagnóstico e do al erta profundos do que entende ser uma era alarmante para a humanidade. $\mathrm{E}$ nesse ponto, distanciando-se dos pós-modernos, afirma que olhar a miséria humana sublimando qualquer al ento de consciência ou dando de ombros à escassez de soluções advinda da descrença da razão e da emancipação, vendo-as como "metanarrativas", implica não apenas cumplicidade, mas um ato de absoluta imoralidade.

Enfim, como sugerimos desde o início, as alternativas mais radicais que se colocam hoje em dia ao funcional ismo em análise organizacional são ao mesmo tempo diversas e multifacetadas, mas também carregam, como qualquer projeto epistemológico, seus próprios dilemas e limitações. Nada é de graça. N ossa esperança é de que, nesta introdução, possamos ter oferecido pistas ao leitor que se inicia no entendimento dessas polêmicas vertentes em estudos organizacionais, e que anseia chegar às suas próprias conclusões.

\section{NOTA}

${ }^{1}$ Apesar de alguns autores brasileiros noutros campos, como em psicologia e educação, usarem o termo "teoria de rede de atores", não nos pareceu que essa tradução esteja suficientemente validada e aceita local mente e, portanto, preferimos a indicação em inglês. Referências ao tema podem ser vistas pelas indicações bibliográficas de Rafael Alcadipani e Christine McLean, na Revista de Administração de Empresas (RAE), v. 42, n. 2, p. 122, 2002.

\section{REFERÊNCIAS BIBLIOGRÁFICAS}

ACKROYD, S. Less bourgeois than thou? A critical review of Studying M anagement Critically. Ephemera: Theory \& Politics in Organization, v. 4, n. 2, p. 165-170, 2004.
ALCADIPANI, R. Réplica: a singularização do plural. Revista de Administração Contemporânea, v. 9, n. 1, p. 213-222, 2005.

ALVESSO N, M.; DEETZ, S. Teoria crítica e abordagens pós-modernas para estudos organizacionais. In: CLEGG, S.; HARDY, C.; NORD, W. (Orgs.). (Organizadores da edição brasileira: CALDAS, M.; FACHIN, R.; FISCHER, T.). Handbook de estudos organizacionais, v. 1: Modelos de análise e novas questões em estudos organizacionais. São Paulo: Atlas, 1999.

ALVESSON, M.; WILLMOTT, H. (Orgs.). Critical Management Studies. London: Sage, 1992.

ALVESSON, M.; WILLMOTT, H. (Orgs.). Critical Management Studies. London: Sage, 2003.

ANDRADE, A. L.; CAPPELLE, M. C. A.; BRITO, M. J., PAULA NETO, A.; VILAS BOAS, L. H. Gênero nas O rganizações: Um estudo de caso no setor bancário. RAE-eletrônica, v. 1, n. 2, art. 22, 2002.

ANDRADE, J. A. Actor-network theory: uma tradução para compreender o relacional e 0 estrutural nas redes interorganizacionais. In: ENCONTRO ANUAL DA ASSO CIAÇÃO NACIONAL DOS PROGRAMASDE PÓS-GRADUAÇÃO E PESQUISA EM ADMINISTRAÇÃO, 27., Atibaia, 2003. Anais. Atibaia, SP: ANPAD, 2003.

BAUMAN, Z. Work, Consumerism and the N ew Poor. Buckingham; PA: Open University Press; London: Sage, 1998.

BAUMAN , Z. Globalização: as conseqüências humanas. Rio de Janeiro: Jorge Zahar Editores, 1999.

BAUMAN, Z. Em busca da política. Rio de Janeiro: JorgeZahar Editores, 2000.

BAUMAN, Z. M odernidadelíquida. Rio de Janeiro: JorgeZahar Editores, 2001.

BERMAN, M. All That Is Solid M elts into Air: The Experience of Modernity. New York: Simon and Schuster, 1982.

BHABHA, H. The Location of Culture. London: Routledge, 1995.

BÖHM, S.; SPOELSTRA, S. N o critique (editorial). Ephemera: Theory \& Politics in Organization, v. 4, n. 2, p. 94-100, 2004.

BURREL, G. Modernism, postmodernism and organizational analysis: the contribution of Michel Foucault. Organization Studies, v. 9, n. 2, p. 221$235,1988$.

BURREL, G. Modernism, postmodernism and organizational analysis: the contribution of Jürgen Habermas. Organization Studies, v. 15, n. 1, p. 145, 1994.

CALÁS, M. B. An/other silent voice? Representing "Hispanic woman" in organizational texts. In: MILLS, A. J.; TANCRED, P. (Org.). Gendering Organizational Analysis. Newbury Park, CA: Sage, 1992. p. 201-221.

CALÁS, M. B.; SMIRCICH, L. Past postmodernism? Reflections and tentative directions. Academy of Management Review, v. 24, n. 4, p. 649-71, 1999.

CALÁS, M. B.; SMIRCICH, L. Do ponto de vista da mulher: abordagens feministas em estudos organizacionais. In: CLEGG, S.; HARDY, C.; NORD, W. (Orgs.). (Organizadores da edição brasileira: CALDAS, M.; FACHIN, R.; FISCHER, T.). Handbook de estudos organizacionais, v. 1: Modelos de análise e novas questões em estudos organizacionais. São Paulo: Atlas, 1999b. p. 275-329. 


\section{MARCELO MILANO FALCÃO VIEIRA •MIGUEL P. CALDAS}

CALDAS, M.; ALCADIPANI, R. (2006) Americanização e pós-colonialismo: a gênese da referência norte-americana na cultura e gestão no Brasil. In: CHANLAT, J. F.; FACHIN, R.; FISCHER, T. (Orgs.). Análise das organizações - Perspectivas latinas, v. 1: Olhar histórico e constatações atuais. Porto Alegre: Editora da UFRGS, 2006 (no prelo).

CALLON, M. Actor-network theory - the market test. In: LAW, J.; HASSARD, J. Actor Network Theory and after. Oxford: Blackwell Publishers, 1999. p. 181-195.

CALVERT, L.; RAMSEY, J. V. Bringing women's voice to research on women in management: a feminist perspective. Journal of $M$ anagement Inquiry, $v .1$, p. 79-88, 1992.

CAPPELLE, M. C. A.; MELO, M. C.; BRITO, M. J. M.; BRITO, M. J. Uma análise da dinâmica do poder e das relações de gênero no espaço organizacional. RAE-eletrônica, v. 3, n. 2, art. 22, 2004.

CASOTTI, L. Marketing moderno econsumidor pós-moderno? In: ENCONTRO ANUAL DA ASSOCIAÇÃO NACIONAL DOS PROGRAMASDE PÓSGRADUAÇÃO E PESQUISA EM ADMINISTRAÇÃO, 22., Foz do Iguaçu, 1998. Anais. Foz do Iguaçu, PR: AN PAD, 1998.

CHIA, R. From modern to postmodern organizational analysis. Organization Studies, v. 16, n. 4, p. 579-604, 1995.

CLEGG, S. R. M odern Organizations: Organization Studies in the Postmodern World. London: Sage, 1990.

COOPER, R. Modernism, postmodernism and organizational analysis: the contribution of Jacques Derrida. Organization Studies, v. 10, n. 4, p. 479-50, 1989.

DAVEL, E.; ALCADIPANI, R. Estudos críticos em Administração: reflexões e contestações sobre a produção brasileira. In: ENCONTRO DE ESTUDOS ORGANIZACIONAIS, 2., Recife, 2002. Anais. Recife: EnEO, 2002.

DAVEL, E.; ALCADIPANI, R. Estudos críticos em Administração: a produção científica brasileira nos anos 90 . Revista de Administração de Empresas, v. 43, n. 4, p. 72-85, 2003.

DERRIDA, J. Writing and Difference. London/ New York: Routledge, 2004.

FARIA, A. Theorizing networks from a critical realist standpoint. In: FLEETW OOD, S.; ACKROYD, S. (Orgs.). Critical Realist Per spectives Applications in Organisation and Management Studies. London: Routledge, 2004.

FARIA, A. Réplica: ampliando questionamentos sobre crítica em Administração. Revista deAdministração Contemporânea, v. 9, n. 1, p. 223-238, 2005 a.

FARIA, A. Realismo crítico em pesquisa em estratégia. In: VIEIRA, M. M. F.; ZOUAIN, D. M. (Orgs.). Pesquisa qualitativa em administração: teoria e prática. Rio de Janeiro: FGV Editora, 2005b.

FARIA, A.; WENSLEY, R. A critical perspective on marketing strategy. In: ENCONTRO ANUAL DA ASSOCIAÇÃO NACIONAL DOS PROGRAMAS DE PÓS-GRADUAÇÃO E PESQUISA EM ADMINISTRAÇÃO, 29., Brasília, 2005. Brasília: AN PAD, 2005.

FARIA, J. H. Poder e participação: a delinqüência acadêmica na interpretação tragtenberguiana. Revista de Administraç̧ão de Empresas, v. 41, n. 3, p. 70-76, 2001.

FARIA, J. H. A economia política do poder. v. 1, v. 2 e v. 3 Curitiba: Juará, 2004.
FARIA, J. H. Universidade, produção científica e aderência social. U niversidade e Sociedade, v. 15, n. 35, p. 13-33, 2005.

FOUCAULT, M. Vigiar epunir: nascimento da prisão. Petrópolis: Vozes, 1987.

FOUCAULT, M. História da sexualidade: a vontade de saber. Rio de Janeiro: Graal, 1988.

GIDDENS, A. The Consequences of M odernity. Stanford, CA: Stanford University Press/ Oxford: Basill Blackwell/ Cambridge: Polity Press, 1991a.

GIDDENS, A. M odernity and SelfIdentity: Self and Society in the Late Modern Age. Cambridge: Polity Press, 1991b.

HARVEY, D. A condição pós-moderna. São Paulo: Edições Loyola, 1993.

HASSARD, J. Sociology and Organization Theory: Positivism, Paradigms and Postmodernity. New York: Cambridge University Press, 1993.

HASSARD, J.; PARKER, M. (Orgs.). Postmodernism and Organization Analysis. London: Sage, 1993.

HERNES, T.; BAKKEN, T. Implications of self-reference: Niklas Luhmann's autopoiesis and organization theory. Organization Studies, v. 24, n. 9, p. 15111535, 2003.

HORKHEIMER, M. Teoria crítica. Buenos Aires: Amorrortu, 1990.

JAMESON, F. Postmodernism, or The Cultural Logic of Later Capitalism. Durham: Duke University Press, 1991.

KAGHAN, W.: PHILLIPS, N. Building the tower of Babel: communities of practice and paradigmatic pluralism in organization studies. Organization, $\mathrm{v}$. 5, p. 191-215, 1998.

KILDUFF, M. Deconstructing O rganizations. Academy of M anagement Review, v. 18, p. 13-31, 1993.

LATOUR, B. Whereare the missing masses? The sociology of a few mundane artifacts. In: BIJKER, W.; LAW, J. (Eds.). Shaping Technology Building Society. Cambridge, MA: MIT Press, 1992. p. 225-259.

LATOUR, B. On technical mediation: philosophy, sociology and genealogy. Common Knowledge, v. 3, n. 2, p. 29-64, 1994.

LATOUR, B. Ciência em ação. São Paulo: Editora Unesp, 1997.

LAW, J. Organizing M odernity. Oxford: Blackwell, 1994.

LAW, J.; HASSARD, J. Actor N etwork Theory and After. Oxford: Blackwell, 1999

LENGLER, J. F. B; VIEIRA, M. M. F.; FACHIN, R. C. Um exercício de desconstrução do conceito e da prática de segmentação de mercado inspirado em Woody Allen. Revista de Administração de Empresas, v. 42, n. 4, p. 84-93, 2002.

LYOTARD, J. F. ThePostmodern Condition: A Report on Knowledge. Minneapolis: University of Minnesota Press, 1984.

MENDES, D. 0 caleidoscópio: modismos e pós-modernidade. In: ENCONTRO ANUAL DA ASSO CIAÇÃO NACIONAL DOS PROGRAMASDE PÓSGRADUAÇÃO E PESQUISA EM ADMINISTRAÇÃO, 28., Curitiba, 2004. Anais. Curitiba, PR: AN PAD, 2004. 
MISOCZKY, M. A. 0 campo da atenção à saúde no Brasil após a Constituição de 1988: uma narrativa de sua produção social. Porto Alegre: Da Casa Editora, 2002.

MISOCZKY, M. A.; ANDRADE, J. A. Uma crítica à crítica domesticada nos estudos organizacionais. Revista deAdministração Contemporânea, v. 25, n. 1, p. 193-211, 2005a.

MISOCZKY, M. A.; ANDRADE, J. A. Tréplica: quem tem medo do fazer acadêmico enquanto práxis? Revista de Administração Contemporânea, v. 25, n. 1, p. 239-245, 2005b.

MOTTA, F. C. P. 0 que é burocracia. São Paulo: Pioneira, 1985.

MOTTA, F. C. P. Teoria das organizações: evolução e crítica. São Paulo: Pioneira, 1986a.

MOTTA, F. C. P. Organização nascente, pré-capitalismo emanufatura. Revista de Administração de Empresa, v. 26, n. 4, p. 19-30, 1986b.

MOTTA, F. C. P. Tecnoburocracia e educação formal. Educação e Sociedade, v. 3, n. 23, p. 50-78, 1986c.

MOTTA, F. C. P. Redes organizacionais e Estado amplo. Revista de Administração de Empresas, v. 27, n. 2, p. 5-13, 1987.

MOTTA, F. C. P. Formas organizacionais do Estado. Revista de Administração de Empresas, v. 28, n. 4, p. 15-32, 1988.

MOTTA, F. C. P. Organização e poder: empresa, Estado e escola. São Paulo: Atlas, 1990.

NORRIS, C. What's Wrong with Postmodernism: Critical Theory and the Ends of Philosophy. Baltimore: Johns Hopkins University Press, 1990.

PAULA, A. P. P. Tragtenberg e a resistência da crítica: ensino e pesquisa na Administração hoje. Revista de Administração de Empresas, v. 41, n. 3, p. 7781, 2001.

PAULA, A. P. P. Tragtenberg revisitado: as inexoráveis harmonias administrativas e a burocracia flexível. Revista de Administração Pública, v. 36, n. 1, p. 127-144, 2002.

PAULA, A. P. P. Repensando os estudos críticos em Administração no Brasil. Revista de Administração de Empresas, v. 44, n. 2, p. 114-115, 2004.

PAULA, A. P. P. N ovas formas de poder e controle nas organizações. Revista de Administração de Empresas, v. 45, n. 3, p. 122-123, 2004.

PAULA, A. P. P. Por uma nova gestão pública: limites e potencialidades da experiência contemporânea. Rio de Janeiro: Editora FGV, 2005.

PAULA, A. P. P. Administração pública brasileira: entre o gerencialismo e a gestão social. Revista de Administração de Empresas, v. 45, n. 1, p. 36-49, 2005.

RAMOS, A. G. A nova ciência das organizações: uma reconceituação da riqueza das nações. Rio de Janeiro: Editora FGV, 1989.

RAM OS, A. G. A redução sociológica. Rio de Janeiro: Editora da UFRJ, 1996.
SEWELL, G.; WILKINSON, B. Someone to watch over me: surveillance, discipline and thejust-in-timelabour process. Sociology, v. 26, p. 271-289, 1992.

SOKAL, A.; BRICM ONT, J. FashionableN onsense: Postmodern Philosophers' Abuse of Science. N ew York: St. Martin's Press, 1998.

SOLÉ, A. Voir autrement le monde. Disponível em «ttp://www.societe-destrategie-asso.fr/artA3.html\#solé>.

SOLÉ, A. Créateurs de mondes: nos possibles, nos impossibles. Paris: Rocher, 2000.

SOUZA, E. G.; FONTANA, E. R. Estruturas de governança em sistemas de compensação e liquidação: uma análise com Actor-N etwork Theory. In: CONGRESSO INTERNACIONAL DE GESTÃO DE TECNOLOGIA E SISTEMAS DE INFORMAÇÃO, 2., São Paulo, 2005, Anais. São Paulo, SP: Contecsi/FEA-USP, 2005.

TEN Ó RIO , F. G. Tem razão a administração? Ensaios de teoria organizacional e gestão social. Ijuí: Editora da Unijuí, 2002a.

TENÓRIO, F. G. Flexibilização organizacional: mito ou realidade? Rio de Janeiro: Editora FGV, 2002b.

TEN Ó RIO, F. G. (N eo)tecnocratas ou (neo)bobos? Eis a questão. In: VIEIRA, M. M. F.; CARVALHO, C. A. Organizações, instituições e poder no Brasil. Rio de Janeiro: Editora FGV, 2003.

TEN ÓRIO, F. G. U m espectro ronda o terceiro setor: o espectro do mercado. Ensaios de Gestão Social. Ijuí: Editora da Unijuí, 2004.

TONELLI, M. J., eALCADIPANI, R. Organizações pós-modernas: uma discussão sobre as novas competências requeridas aos gestores e a maquiagem do self. In: ENCONTRO ANUAL DA ASSOCIAÇÃO NACIONAL DOSPROGRAMASDE PÓS-GRADUAÇÃO E PESQUISA EM ADMINISTRAÇÃO, 24, Florianópolis, 2000. Anais. Florianópolis, SC: AN PAD, 2000.

TOWNEY, B. Foucault, power/knowledge, and its relevance for human resource management. Academy of Management Review, v. 18, p. 518-545, 1993.

VIEIRA, E. F.; VIEIRA, M. M. F. Espaços econômicos: geoestratégia, poder e gestão do território. Porto Alegre: Sagra-Luzzatto, 2003.

VIEIRA, E. F.; VIEIRA, M. M. F. A dialética da pós-modernidade: a sociedade em transformação. Rio de Janeiro: Editora FGV, 2004.

WHITE, S.K. The Recent Work of Jürgen Habermas: Reason, Justice and Modernity. Cambridge/N ew York: Cambridge University Press, 1988.

WACQUANT, L. Critical thought as solvent of doxa. Constellations, v. 11, n. $1,2004$.

WOOD JR., T. N ota técnica: frutas maduras em um supermercado de idéias mofadas. In: CLEGG, S.; HARDY, C.; N ORD, W. (Orgs.). (Organizadores da edição brasileira: CALDAS, M.; FACHIN, R.; FISCHER, T.). Handbook de estudos organizacionais, v.1: Modelos de análise e novas questões em estudos organizacionais. São Paulo: Atlas, 1999.

YOUNG, R. Postcolonialism: An Historical Introduction. Oxford: Blackwell Publishers, 2001.

\section{Artigo convidado. Aprovado em 22.12.2005}

70 - ORAE - VOL 46 • No1 